\title{
Putative association of RUNX1 polymorphisms with IgE levels in a Korean population
}

\author{
Soo-Cheon Chae ${ }^{1}$, Byung Lae Park ${ }^{4}$, \\ Choon-Sik Park ${ }^{5}$, Ha-Jung Ryu ${ }^{6}$, \\ Yun-Sik Yang ${ }^{1,2}$, Soo Ok Lee ${ }^{4}$, \\ Yoo Hyun Choi ${ }^{4}$, Eun Mi Kim ${ }^{4}$, \\ Soo Taek $\mathrm{Uh}^{5}$, Young Hoon $\mathrm{Kim}^{5}$, \\ Ka-Kyung Kim ${ }^{6}$, Bermseok $\mathrm{Oh}^{6}$, \\ Hun-Taeg Chung ${ }^{1,3}$, Kuchan $\mathrm{Kimm}^{6,7}$ and \\ Hyoung Doo Shin ${ }^{4}$
}

\author{
${ }^{1}$ Genome Research Center for Immune Disorders \\ ${ }^{2}$ Department of Ophthalmology \\ ${ }^{3}$ Department of Microbiology and Immunology \\ Wonkwang University School of Medicine \\ Iksan 570-749, Korea \\ ${ }^{4}$ Department of Genetic Epidemiology \\ SNP Genetics, Inc. \\ Seoul 153-803, Korea \\ ${ }^{5}$ Asthma Genome Research Group \\ Soonchunhyang University Hospital \\ Bucheon 420-021, Korea \\ ${ }^{6}$ National Genome Research Institute \\ National Institute of Health \\ Seoul 122-701, Korea \\ ${ }^{7}$ Corresponding author: Tel, 82-2-380-1522; \\ Fax, 82-2-354-1063; E-mail, k2kimm2@nih.go.kr
}

Accepted 14 August 2006

Abbreviations: BA, Bronchial asthma; IgE, immunoglobulin E; NC, normal control

\begin{abstract}
RUNX1, a member of the runt domain gene family of transcription factors, encodes a heterodimeric transcription factor and regulates the expression of various genes related to hematopoiesis and myeloid differentiation. RUNX1 has been one of the target genes for research into various autoimmune disea ses due to its properties as a transcription factor and functional distribution for chromosomal translocation. In an effort to identify additional gene polymorphisms in which variants have been implicated in asthma, we investigated the genetic polymorphisms in RUNX1 to evaluate it as a potential candidate gene for a host genetic study of asthma and IgE production. We identified 19 sequence variants
\end{abstract}

by direct DNA sequencing in 24 individuals of which four common variants were selected for genotyping in our asthma cohort (1,055 asthmatic patients, 384 normal controls). Using logistic regression analysis for association with the risk of asthma, while controlling for age, gender, and smoking status as covariates, no significant associations with the risk of asthma were detected. However, two polymorphisms in the promoter region (-2084G $>C$ and $-1282 G>A)$ showed a marginal association with total IgE levels $(0.03$ and 0.03 in recessive models, respectively). Our findings suggest that polymorphisms in RUNX1 might be one of the genetic factors for the regulation of IgE production

Keywords: asthma; core binding factor alpha 2 subunit; immunoglobulin E; polymorphism, single nucleotide

\section{Introduction}

Asthma is a common and heterogeneous respiratory disease characterized by reversible airway obstruction caused by chronic inflammation of the airways. Asthma and related phenotypes are thought to be complex traits caused by an interaction of multiple disease susceptibility genes and environmental factors. Bronchial hyperresponsiveness is a characteristic feature of asthma, and serum lgE levels are closely associated with asthma development. The development of asthma is determined by an interaction between host genetic susceptibility and a variety of environmental factors (Burrows et al., 1989; Kim et al., 1999; Koh et al., 2000; Ahmadi and Goldstein 2002).

Runt-related transcription factor 1 (RUNX1, MIM 151358) on chromosome $21 q 22$ is a member of the runt domain gene family of transcription factors, and encodes a heterodimeric transcription factor containing an N-terminal DNA-binding domain (Kania et al., 1990; Roumier et al., 2003). RUNX1 is expressed in all hematopoietic lineages and regulates the expression of various genes specific for hematopoiesis and myeloid differentiation, such as IL3 and CSF2, as a key regulator of hematopoiesis through interactions with cofactors (Takahashi et al., 1995; Uchida et al., 1997; Lutterbach and Hiebert 2000; Roumier et al., 2003). RUNX1 is one of the target genes for various autoimmune diseases. 
Chromosomal translocation of $R U N X 1$ is most frequently found in leukemia, and different types of translocation of the RUNX1 gene corresponding to the production of different chimeric products and subtypes of acute myeloid leukemia have also been reported (Yamada et al., 2004; Skubitz et al., 2005). Thus, RUNX1 seems to be implicated in acute leukemia through various pathogenic mechanisms. Recent reports have also demonstrated that the RUNX1 gene is associated with several inflammatory and autoimmune disorders, such as systemic lupus erythematosus (SLE), psoriasis, and rheumatoid arthritis (RA) (Prokunina et al., 2002; Helms et al., 2003; Tokuhiro et al., 2003). Additional aspects of the RUNX1 gene, such as point mutations, amplifications, and germ-line mutations, are also known to be factors for leukemia, platelet disorders, and myelodysplasia (Osato et al., 1999; Song et al., 1999; Niini et al., 2000).

Although the functional importance of the RUNX1 gene in immune disorders has been studied, the genetic associations of RUNX1 polymorphisms are still obscure. Previous research has focused on genetic studies of the RUNX1 binding sites of interacting candidate genes, probably because of the functional features of $R U N X 1$ as a transcription factor. It has recently been demonstrated that the intronic polymorphism of RUNX1 is significantly associated with the susceptibility of RA in a Japanese population (Tokuhiro et al., 2003). Based on the biological properties involved in the essential role of mediating various inflammatory responses, it is hypothesized that RUNX1 plays an important role in asthma development and the level of lgE.

We performed extensive screening of RUNX1 by direct sequencing to detect polymorphisms and examined the genetic association with the risk of asthma and the level of lgE. Here, we present 19 genetic polymorphisms found in RUNX1 and the results of an association study in a Korean asthma cohort.

\section{Materials and Methods}

\section{Subjects and measures}

Subjects were recruited from the Asthma Genome Research Center, which includes three hospitals in Korea (Soonchunhyang University, Seoul; Bucheon, and Chunan Hospitals). Ethical approvals were obtained from the institutional review board of Soonchunhyang University hospital. All patients exhibited clinical symptoms and physical examination results compatible with asthma. Each patient showed airway reversibility as documented by an inhalant bronchodilator-induced improvement of more
Table 1. Clinical profiles of asthmatic and normal subjects $(n=1,439)$.

\begin{tabular}{lcc}
\hline \multicolumn{1}{c}{ Clinical profiles } & $\begin{array}{c}\text { Normal } \\
\text { controls }\end{array}$ & Asthmatics \\
\hline Number of subjects & 384 & 1055 \\
Age [mean (range)] & $44.8(6-83)$ & $48.7(4-86)$ \\
Sex (male/female) & $169 / 215$ & $423 / 632$ \\
Current smoker (\%) & $29.11 \%$ & $34.27 \%$ \\
FVC1\%, predicted & $93.0 \pm 11.9$ & $83.5 \pm 18.2$ \\
FEV1\%, predicted* & $102.1 \pm 14.8$ & $80.1 \pm 22.7$ \\
PC 20, methacholine (mg/ml)* & $23.4 \pm 4.8$ & $6.2 \pm 8.6$ \\
Log [total lgE (IU/ml)] $^{*}$ & $1.71 \pm 0.63$ & $2.13 \pm 0.65$ \\
Peripheral blood eosinophil & $2.55 \pm 2.10$ & $5.37 \pm 5.37$ \\
(\%) $^{*}$ & 34.85 & 56.87 \\
\hline Positive rate of atopy (\%)*
\end{tabular}

${ }^{*} P$ value $<0.001$ for difference between asthma patients and normal controls

than $15 \%$ of $F E V 1$, and/or an airway hyperreactivity of less than $10 \mathrm{mg} / \mathrm{ml}$ of methacholine. No subject had used systemic or high dose inhaled steroids during the 4 weeks prior to the examination of the serum IgE. Normal subjects were recruited from patient spouses and from the general population by negative answers to a screening questionnaire for respiratory symptoms. Normal subjects exhibited normal findings on a simple chest radiogram and also had an FEV1 level greater than $75 \%$ predicted, the provocation concentration that causes a fall in the FEV1 level of $20 \%\left(\mathrm{PC}_{20}\right)$ by methacholine greater than $10 \mathrm{mg} / \mathrm{ml}$. Total $\mathrm{lgE}$ was measured using the UniCAP system (Pharmacia Diagnostics, Sweden). Atopy was defined as a wheal reaction by allergen extract equal to or greater than the reaction by histamine $(1 \mathrm{mg} / \mathrm{ml})$, or $3 \mathrm{~mm}$ in diameter. Patient clinical profiles are summarized in Table 1.

\section{Sequencing analysis of the human RUNX1}

We sequenced all exons, their boundaries, and the promoter region $(\sim 1.5 \mathrm{~kb})$, to discover single-nucleotide polymorphisms (SNPs) in 24 Korean DNA samples using an ABI PRISM 3730 DNA analyzer (Applied Biosystems, Foster City, CA). Eighteen primer sets for the amplification and sequencing analysis were designed based on GenBank sequences (Ref. Seq. of RUNX1 mRNA: NM_001754 and contig: NT_011512). 
A Map of RUNX1 (runt-related transcription factor 1 (acute myeloid leukemia 1; aml1 oncogene)) on chromosome 21q22.3 (262 kb)

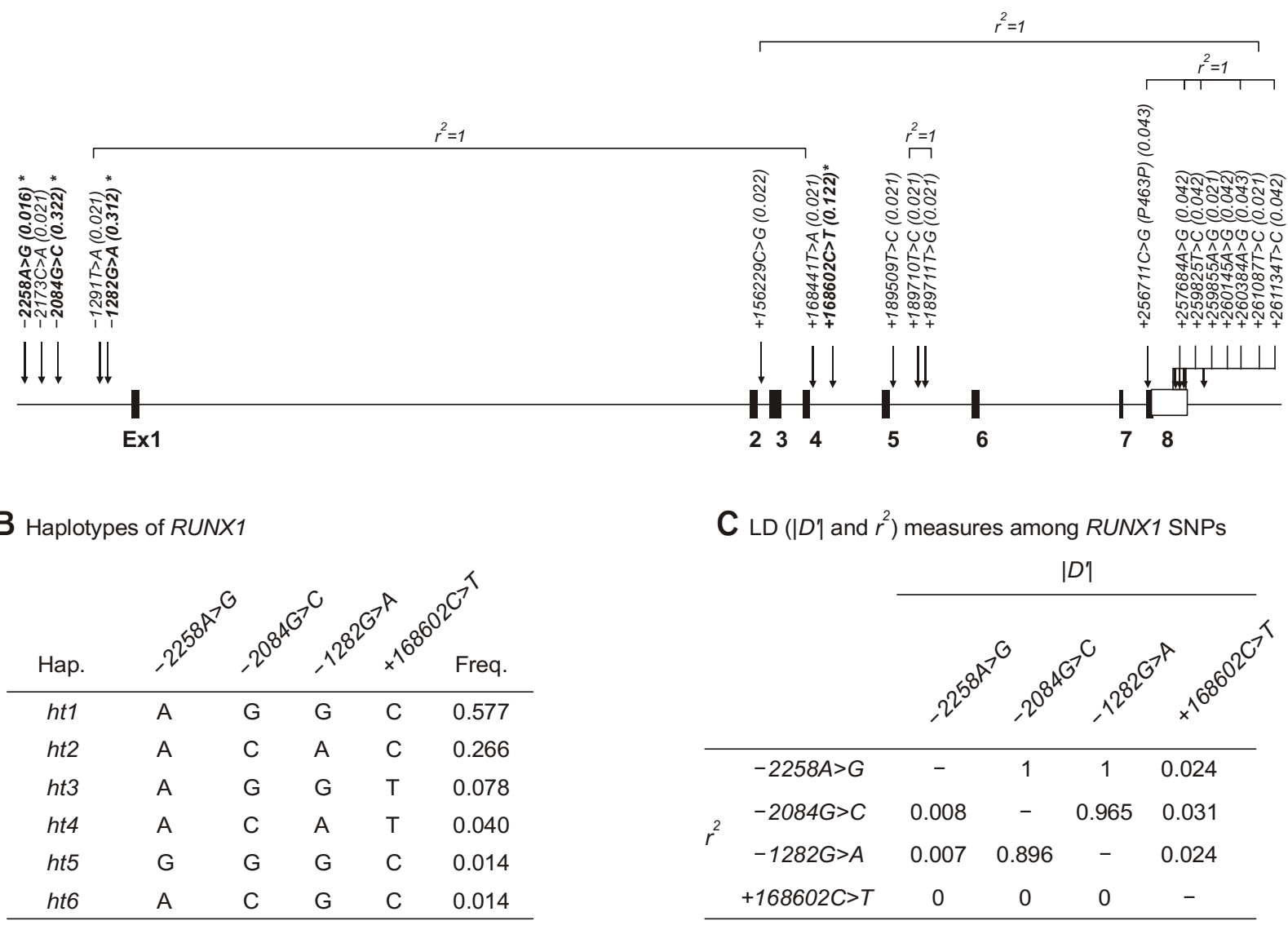

Figure 1. Gene maps and haplotypes of RUNX1. Coding exons are marked by black blocks, and 5' and 3' UTRs by white blocks. The first base of the translation start site is denoted as nucleotide +1 . Asterisks indicate polymorphisms genotyped in a larger population $(n=1,439)$. The frequencies of polymorphisms not subjected to larger-scale genotyping were based on sequence data $(n=24)$. (A) Polymorphisms identified in RUNX1 on chromosome 21q22.3 (Ref. Genome Seq. NT_011512). (B) Haplotypes of RUNX1. (C) Linkage disequilibrium coefficients (|D'| and $\left.r^{2}\right)$ among RUNX1 polymorphisms.

Table 2. Logistic analysis of RUNX1 polymorphisms with the risk of asthma while controlling for age and sex as covariates among asthmatic and normal subjects.

\begin{tabular}{|c|c|c|c|c|c|c|}
\hline \multirow{2}{*}{ Loci } & \multirow{2}{*}{ Position } & \multirow{2}{*}{ rs\# } & \multirow{2}{*}{$\begin{array}{c}\text { BA } \\
(n=997)\end{array}$} & \multirow{2}{*}{$\begin{array}{c}\mathrm{NC} \\
(n=353)\end{array}$} & \multicolumn{2}{|c|}{ Co-dominant } \\
\hline & & & & & OR $(95 \% \mathrm{Cl})$ & $P$ \\
\hline$-2258 A>G$ & Promoter & rs9977916 & 0.016 & 0.016 & $0.82(0.43-1.56)$ & 0.55 \\
\hline$-2084 G>C$ & Promoter & rs12626613 & 0.317 & 0.330 & $0.96(0.80-1.14)$ & 0.62 \\
\hline$-1282 G>A$ & Promoter & rs2071029 & 0.309 & 0.330 & $0.91(0.75-1.11)$ & 0.37 \\
\hline$+168602 C>T$ & Intron4 & rs2298351 & 0.129 & 0.123 & $1.03(0.81-1.31)$ & 0.82 \\
\hline h1 (AGGC) & - & - & 0.580 & 0.546 & -0.611 & 0.54 \\
\hline h2 (ACAC) & - & - & 0.260 & 0.288 & 0.984 & 0.33 \\
\hline h3 (AGGT) & - & - & 0.076 & 0.089 & 0.204 & 0.84 \\
\hline
\end{tabular}

Genotype distributions and $P$-values for logistic analyses of three alternative models (co-dominant, dominant, and recessive models) controlling for age and sex as covariates are shown. $P$-values of haplotype associations were calculated by the algorithm developed by Schaid et al., (Haplo.Score), while controlling for age and sex as covariates. Haplotypes with a frequency $>0.05$ are presented. 
Table 3. Regression analyses of log-transformed total IgE as a function of RUNX1 polymorphisms in asthmatics.

\begin{tabular}{|c|c|c|c|c|c|c|c|c|}
\hline Loci & Position & rs\# & $\mathrm{C} / \mathrm{C}$ & $\mathrm{C} / \mathrm{R}$ & $\mathrm{R} / \mathrm{R}$ & $P a$ & $P b$ & $P c$ \\
\hline$-2258 A>G$ & Promoter & rs9977916 & $944(2.14 \pm 0.65)$ & $32(2.06 \pm 0.74)$ & $1(1.81)$ & 0.30 & 0.37 & 0.33 \\
\hline$-2084 G>C$ & Promoter & rs12626613 & $446(2.16 \pm 0.63)$ & $447(2.07 \pm 0.67)$ & $89(2.26 \pm 0.67)$ & 0.71 & 0.08 & 0.03 \\
\hline$-1282 G>A$ & Promoter & rs2071029 & $462(2.15 \pm 0.63)$ & $429(2.07 \pm 0.68)$ & $88(2.28 \pm 0.66)$ & 0.86 & 0.13 & 0.03 \\
\hline$+168602 C>T$ & Intron4 & rs2298351 & $740(2.13 \pm 0.66)$ & $213(2.10 \pm 0.63)$ & $17(2.23 \pm 0.54)$ & 0.98 & 0.76 & 0.29 \\
\hline$h 1$ (AGGC) & - & - & 0.739 & - & - & 0.46 & - & - \\
\hline$h 2(A C A C)$ & - & - & 0.019 & - & - & 0.98 & - & - \\
\hline h3 (AGGT) & - & - & 0.287 & - & - & 0.77 & - & - \\
\hline
\end{tabular}

Genotype distributions, means, and standard deviations (SD) of Log (total $\operatorname{lgE}$ ), and $P$-values for regression analyses of three alternative models (co-dominant, dominant, and recessive models) are shown. $P$-values of haplotype associations were calculated by the algorithm developed by Schaid et al., (Haplo.Score), while controlling for age and sex as covariates. Haplotypes with a frequency $>0.05$ are presented.

\section{Genotyping with fluorescence polarization detection}

For genotyping of polymorphic sites, amplifying primers and probes were designed for TaqMan (Livak 1999). Primer Express (Applied Biosystems) was used to design both the PCR primers and the MGB TaqMan probes. One allelic probe was labeled with FAM dye and the other with fluorescent VIC dye.

\section{Statistics}

$\chi^{2}$ tests were used to determine whether individual variants were in equilibrium at each locus in the population (Hardy-Weinberg equilibrium). We used both Lewontin's $D^{\prime}\left(\left|D^{\prime}\right|\right)$ (Hedrick 1987) and $r^{2}$ as measures of linkage disequilibrium between all pairs of biallelic loci. Haplotypes of each individual were inferred using software (PHASE) based on the algorithm developed by Stephens et al. (2001), which uses a Bayesian approach that incorporates a priori expectations of haplotypic structures from population genetics and coalescent theory. The genotype distribution of RUNX1 SNPs and haplotypes among the asthmatics and the normal subjects was analyzed using logistic regression models controlling for age (continuous value), sex (male $=0$, female $=1$ ), and smoking status (nonsmoker $=0$, ex-smoker $=1$, smoker $=2$ ) as covariates. Multiple regressions, while adjusting for age, sex, and smoking status, were used for association analyses of total lgE levels. $P$ values of haplotype associations were calculated using the algorithm developed by Schaid et al. (2002) (Haplo.Score).

\section{Results and Discussion}

RUNX1, a member of the runt domain gene family of transcription factors, encodes a heterodimeric transcription factor and regulates the expression of various genes related to hematopoiesis and myeloid differentiation (Kania et al., 1990; Takahashi et al., 1995; Uchida et al., 1997; Lutterbach and Hiebert 2000; Roumier et al., 2003). RUNX1 proteins contain a highly evolutionary conserved runt domain, which is responsible both for heterodimerization with the CBF (Core Binding Factor) and for binding with DNA (Downing 2001). RUNX1 has been a target gene for research into various autoimmune diseases due to its properties as a transcription factor and functional distribution for chromosomal translocation. Translocation of the RUNX1 gene corresponds to production of different chimeric products and subtypes of acute myeloid leukemia (Yamada et al., 2004; Skubitz et al., 2005).

We performed direct DNA sequencing of the RUNX1 gene in 24 unrelated individuals, and identified 19 sequence variants of RUNX1 within exons and their flanking regions. Five in the $5^{\prime}$ region, seven in exons, six in introns, and one in the 3 ' region (Figure $1 \mathrm{~A}$ ). Four polymorphisms were selected for larger-scale genotyping based on locations, LDs, frequencies, and, haplotype tagging status. The frequencies of the four SNPs were 0.016 $(-2258 A>G), 0.322(-2084 G>C), 0.312(-1282 G>A)$, and $0.214(+168602 C>T)(n=1,439)$. This information, including frequencies, heterozygosity, and HardyWeinberg equilibrium, is available on our website (http://www.snp-genetics.com/reference/Supplement ary_information_to_RUNX1.doc). Six haplotypes of RUNX1 were constructed, and haplotypes that had frequencies of less than $5 \%$ were excluded from the statistical analysis to avoid redundant statistical tests (Figure 1B). Linkage disequilibrium coefficients (|D'|) and $r^{2}$ values among polymorphisms were also calculated, and haplotypes that were equivalent with single polymorphisms or had frequencies of less than $5 \%$ were excluded from further statistical analysis.

Allele frequencies of polymorphisms and common haplotypes were compared between the patients 
and the normal controls using logistic regression models. The genetic polymorphisms of RUNX1 showed no association with asthma development (Table 2). However, two polymorphisms $(-2084 \mathrm{G}>\mathrm{C}$ and $-1282 \mathrm{C}>\mathrm{T}$ ) in the regulatory region, which were in tight linkage ( $\left|D^{\prime}\right|=0.965$ and $\left.r^{2}=0.896\right)$, showed marginal associations with the $\lg E$ levels among asthmatics $(0.03$ and 0.03 in recessive models, respectively; Table 3 ).

Previous research has focused on genetic studies of RUNX1 binding sites of interacting candidate genes, probably because of the functional features of RUNX1 as a transcription factor. Based on interest in this area, RUNX1 has been investigated for its functional relationship with various inflammatory and autoimmune diseases, such as leukemia, SLE, psoriasis, and RA (Miyoshi et al., 1995; Prokunina et al., 2002; Helms et al., 2003; Tokuhiro et al., 2003). The genetic associations of RUNX1 polymorphisms with the above diseases have not been well defined. Nevertheless, it is clear that the RUNX1 gene plays an important role in immune responses. We found that polymorphisms in promoter regions of the RUNX1 gene were associated with the production of total IgE. In addition, based on an in silico study using the TRANSFAC database, core and matrix similarities of the MAZ (MYC-associated zinc finger protein)-binding site to the sequence surrounding the minor allele -2084C (CССТССCT, where the fifth nucleotide is polymorphic) were predicted to be 0.95 and 0.90 . The major $-2084 G$ allele (CCCTCGCT) lost both similarities (Heinmeyer et al.).

The effects of RUNX1 polymorphisms on the production of IgE were not dramatic. When Bonferroni corrections were strictly adopted, associated $P$ values were not significant (the threshold of significance was $0.007 ; 7$ polymorphisms and 1 phenotype were analyzed). However, there was a chance of type 1 error due to multiple comparisons. Considering that the comparisons were not totally independent of each other due to tight LDs among SNPs/haplotypes, the significance of associations with $\operatorname{lgE}$ production among asthmatic patients is noteworthy. Further biological and/or functional evidence of polymorphisms in the regulatory region of the RUNX1 gene is needed to confirm our suggestive associations of RUNX1 polymorphisms with asthma.

In summary, we identified 19 sequence variants of RUNX1 and examined the association with risk of asthma and $\operatorname{lgE}$ production among asthmatic patients. Genetic analyses of RUNX1 in asthmatic patients revealed putative associations of genetic polymorphisms with the production of lgE.

\section{Acknowledgment}

This work was supported by a grant from the Korea Health 21 R\&D Project, by the Ministry of Health \& Welfare (01-PJ3-PG6-01GN09-003 and 01-PJ3-PG601GN04-003), and a grant from the National Institute of Health, Korea.

\section{References}

Ahmadi KR, Goldstein DB. Multifactorial diseases: asthma genetics point the way. Curr Biol 2002;12:R702-4

Burrows B, Martinez FD, Halonen M, Barbee RA, Cline MG. Association of asthma with serum IgE levels and skin-test reactivity to allergens. N Engl J Med 1989;320:271-7

Downing JR. AML1/CBFbeta transcription complex: its role in normal hematopoiesis and leukemia. Leukemia 2001;15: 664-5

Hedrick PW. Gametic disequilibrium measures: proceed with caution. Genetics 1987;117:331-41

Heinemeyer T, Wingender E, Reuter I, Hermjakob H, Kel AE, Kel OV, Ignatieva EV, Ananko EA, Podkolodnaya OA, Kolpakov FA, Podkolodny NL, Kolchanov NA. Databases on transcriptional regulation: TRANSFAC, TRRD and COMPEL. Nucleic Acids Res 1998;26:362-7

Helms C, Cao L, Krueger JG, Wijsman EM, Chamian F, Gordon D, Heffernan M, Daw JA, Robarge J, Ott J, Kwok PY, Menter A, Bowcock AM. A putative RUNX1 binding site variant between SLC9A3R1 and NAT9 is associated with susceptibility to psoriasis. Nat Genet 2003;35:349-56

Kania MA, Bonner AS, Duffy JB, Gergen JP. The Drosophila segmentation gene runt encodes a novel nuclear regulatory protein that is also expressed in the developing nervous system. Genes Dev 1990;4:1701-13

Kim YK, Cho SH, Koh YY, Son JW, Jee YK, Lee MH, Min KU, Kim YY. Skin reactivity to inhalant allergens, total serum IgE levels, and bronchial responsiveness to methacholine are increased in parents of nonatopic asthmatic children. J Allergy Clin Immunol 1999;104:311-6

Koh YY, Jeong JH, Kim CK, Kim YK, Jee YK, Cho SH, Min KU, Kim YY. Atopic status and level of bronchial responsiveness in parents of children with acute bronchiolitis. J Asthma 2000;37:709-17

Livak KJ. Allelic discrimination using fluorogenic probes and the 5 ' nuclease assay. Genet Anal 1999;14:143-9

Lutterbach B, Hiebert SW. Role of the transcription factor AML-1 in acute leukemia and hematopoietic differentiation. Gene 2000;245:223-35

Miyoshi H, Ohira M, Shimizu K, Mitani K, Hirai H, Imai T, Yokoyama K, Soeda E, Ohki M. Alternative splicing and genomic structure of the AML1 gene involved in acute myeloid leukemia. Nucleic Acids Res 1995;23:2762-2769.

Niini T, Kanerva J, Vettenranta K, Saarinen-Pihkala UM, Knuutila S. AML1 gene amplification: a novel finding in childhood acute lymphoblastic leukemia. Haematologica 


\section{0;85:362-366.}

Osato M, Asou N, Abdalla E, Hoshino K, Yamasaki H, Okubo T, Suzushima H, Takatsuki K, Kanno T, Shigesada K, Ito Y. Biallelic and heterozygous point mutations in the runt domain of the AML1/PEBP2alphaB gene associated with myeloblastic leukemias. Blood 1999;93:1817-24

Prokunina L, Castillejo-Lopez C, Oberg F, Gunnarsson I, Berg $L$, Magnusson V, Brookes AJ, Tentler D, Kristjansdottir $H$, Grondal G, Bolstad AI, Svenungsson E, Lundberg I, Sturfelt G, Jonssen A, Truedsson L, Lima G, Alcocer-Varela J, Jonsson R, Gyllensten UB, Harley JB, Alarcon-Segovia D, Steinsson $\mathrm{K}$, Alarcon-Riquelme ME. A regulatory polymorphism in PDCD1 is associated with susceptibility to systemic lupus erythematosus in humans. Nat Genet 2002;32:666-9

Roumier C, Fenaux $P$, Lafage $M$, Imbert M, Eclache V, Preudhomme C. New mechanisms of AML1 gene alteration in hematological malignancies. Leukemia 2003;17:9-16

Schaid DJ, Rowland CM, Tines DE, Jacobson RM, Poland G. A. Score tests for association between traits and haplotypes when linkage phase is ambiguous. Am J Hum Genet 2002; 70:425-34

Skubitz KM, Cheng EY, Clohisy DR, Thompson RC, Skubitz AP. Differential gene expression in liposarcoma, lipoma, and adipose tissue. Cancer Invest 2005;23:105-18

Song WJ, Sullivan MG, Legare RD, Hutchings S, Tan X, Kufrin D, Ratajczak J, Resende IC, Haworth C, Hock R, Loh M, Felix
C, Roy DC, Busque L, Kurnit D, Willman C, Gewirtz AM, Speck NA, Bushweller JH, Li FP, Gardiner K, Poncz M, Maris JM, Gilliland DG. Haploinsufficiency of CBFA2 causes familial thrombocytopenia with propensity to develop acute myelogenous leukaemia. Nat Genet 1999;23:166-75

Stephens M, Smith NJ, Donnelly P. A new statistical method for haplotype reconstruction from population data. Am J Hum Genet 2001;68:978-89

Takahashi A, Satake M, Yamaguchi-Iwai Y, Bae SC, Lu J, Maruyama M, Zhang YW, Oka H, Arai N, Arai K, et al., Positive and negative regulation of granulocyte-macrophage colonystimulating factor promoter activity by AML1-related transcription factor, PEBP2. Blood 1995;86:607-16

Tokuhiro S, Yamada R, Chang X, Suzuki A, Kochi Y, Sawada T, Suzuki M, Nagasaki M, Ohtsuki M, Ono M, Furukawa $H$, Nagashima M, Yoshino S, Mabuchi A, Sekine A, Saito S, Takahashi A, Tsunoda T, Nakamura Y, Yamamoto K. An intronic SNP in a RUNX1 binding site of SLC22A4, encoding an organic cation transporter, is associated with rheumatoid arthritis. Nat Genet 2003;35:341-8

Uchida $H$, Zhang J, Nimer SD. AML1A and AML1B can transactivate the human IL-3 promoter. J Immunol 1997;158: 2251-8

Yamada R, Tokuhiro S, Chang X, Yamamoto K. SLC22A4 and RUNX1: identification of RA susceptible genes. J Mol Med 2004;82:558-64 